\title{
A Mini Review: Seaweeds Negotiate a Vital Risk Factor of Cardiovascular Disease
}

\author{
Suparna Roy* \\ Centre of Advanced Study in Marine Biology, Faculty of Marine Sciences, Annamalai University, India \\ *Corresponding author: Suparna Roy, Centre of Advanced Study in Marine Biology, Faculty of Marine Sciences, Annamalai \\ University, Tamilnadu, India
}

\begin{abstract}
The high blood cholesterol level is one of the major risk factors of coronary heart disease. The total lipid includes total cholesterol, high-density lipoprotein cholesterol, low-density lipoprotein cholesterol and triglycerides. The high-density lipoprotein cholesterol is good for the heart health; the high level of the high-density lipoprotein cholesterol is helpful to our health. But the high level of the low density lipoprotein cholesterol is responsible for gradual deposition of cholesterol along the inner wall of arteries which followed some serial change to develop atherosclerosis and blockage in the arteries to promote the development of cardiovascular pathogenesis which is consider also the major risk factor for heart failure. The low-density lipoprotein cholesterol value should be below $100 \mathrm{mg} / \mathrm{dL}$. The low-density lipoprotein cholesterol level sometimes become high in our body due to uptake of the high amount of food with saturated and trans-fat. The food habit in different parts of the world is not adequate to prevent and reduce the health hazards and hence it is believed that food habit is the basic reason for the major health problems such as cardiac disease, obesity, diabetes, hepatic disorder and related diseases for global populations. Research shows appropriate fatty acids composition of some marine macro algae is very useful to prevent cardiovascular disease development. Likewise, marine macro algae are composed of adequate amount of proteins, carbohydrates, fatty acids, peptides, minerals, vitamins, long chain molecules, hydrocolloids which will also negotiate nutritional deficiencies for uptake marine macro algae as food items or food ingredients. So, marine macro algae may be use as cardio-protective biomedicine in future after detailed analysis and critical evaluation. The fatty acids compositions and the cholesterol lowering activity of some seaweed are discussed in brief.
\end{abstract}

Keywords: Cholesterol; Low density lipoprotein Cholesterol; Saturated fat; Marine macro algae; Cardio protective

\section{Introduction}

The metabolic syndrome including lipid metabolism disorder is nowadays major cause of death worldwide; it's the underlying causes of cardiovascular disease development. In mammals, due to metabolism, the derived bioactive metabolic product elongates and desaturates with the help of two major essential Omega-3 fatty acids such as $\alpha$-linolenic acid and linoleic acid. The two major underlying causes of cardiovascular disease, the leading cause of death are disorders of lipid metabolism and metabolic syndrome. In mammals' essential fatty acids (n-3) ALA [18:3(n$3)]$ and (n-6) LA [18:2(n-6)] are required for elongation and desaturation of more bioactive derivatives of metabolic product. The long chain fatty acids EPA [20:5 (n-3), (n-3) DHA [22:6 (n-3) and arachidonic acid [20:4 (n-6) can acquire by oral intake. It has been reported that (n-3) fatty acids has specific cardiovascular benefits in terms of reducing cardiac death from arrhythmias, lowering triglycerides, antithrombotic, anti-inflammatory and antihypertensive effects [1]. Tran's isomers of fatty acids, formed by the partial hydrogenation of vegetable oils to produce margarine and vegetable shortening, increase the ratio of plasma low-densitylipoprotein to high density- lipoprotein cholesterol, so it is possible that they adversely influence risk of coronary heart disease (CHD). Additional control for established CHD risk factors, multivitamin use, and intakes of saturated fat, monounsaturated fat, and linoleic acid, dietary cholesterol, vitamins $\mathrm{E}$ or $\mathrm{C}$, carotene, or fibre did not change the relative risk substantially. The association was stronger for the 69181 women whose margarine consumption over the previous 10 years had been stable (1 67 [105-2-66], p for trend $=0002$ ). Intakes of foods that are major sources of Trans isomers (margarine, cookies, cake, and white bread) were each significantly 
associated with higher risks of CHD. These findings support the hypothesis that consumption of partially hydrogenated vegetable oils may contribute to occurrence of CHD. The cholesterol level below and above optimum level causes membrane disruption, necrosis and apoptosis. Cells reduce cholesterol level through convert of cholesterol into cholesteryl esters and cholesterol efflux through various intracellular transporters ATP binding protein such as Scavenger receptor type B1, G1(ABCG1) and A1 (ABCA1). Seaweeds fatty acids composition is favoured to reduce cholesterol level by combine with it and transforming it as cholesteryl esters. So, in this mini-review author precisely discuss regarding seaweeds and its role to negotiate cardiovascular risk factors.

\section{Fatty Acids Composition of Marine Macro Algae Chlorophyta}

The Arctic Chlorophyta Prasiola crispa contains 18:3(n-3), 18:2(n-6) PUFA and 18:1(n-7), 18:2(n-6) PUFA are present in Lambia antarctica [2]. Caulerpa lentillifera contains 16.76\% PUFA [3]. Green algae show high level of alpha linolenic acid ( $\omega 3$ C18:3) but red and brown algae are rich in eicosapentaenoic acid (EPA, $\omega 3$, 20:3) and arachidonic acid (AA, $\omega 6$ C20:4). Spirulin contain gamma linolenic acid (GLA) 20 to $25 \%$ of its total lipidic fraction. Gamma Linolenic acid is the precursor of prostaglandins, leucotriens and thromboxans which helps in modulation of immunological, inflammatory and cardio-vascular responses [4].

Table 1: Fatty Acids Composition of Seaweeds (\% Of Dry Wt.).

\section{Phaeophyta}

Polyunsaturated fatty acids 18:4(n-3), 20:5(n-3), 20:4 (n-6), 18:3(n-3) and 18:2 (n-6); saturated fatty acids 16:0 are present in different species of Phaeophyta of Arctic and Antarctic area. Desmanestia muelleri sporophytes contain 11.1\% 16:1(n-5) monounsaturated fatty acids but gametophytes contain double amount of 18:2(n-6) and 18:3 (n-3) [2] Sargassum polycysticum contains 20.34\% PUFA [3]. The edible seaweed Sargassum fusiforme contains dietary phytosterols which is well-known antiatherosclerotic mentioned in traditional Chinese medicine.

\section{Rhodophyta}

Some species of Rhodophyta collected from Arctic and Antarctic area contain abundant amount of 20:5 (n-3) polyunsaturated fatty acids and 16:0 saturated fatty acids such as 20:5(n-3) $67.3 \%$ in Palmaria palmata and $60.3 \%$ in Audouinella purpurea. Fatty acids 16:1(n-7) present in considerable amount 39.9\% in Ptilota gunneri, $32.7 \%$ in Rhodymenia subantarctica. Fatty acid 20:4(n-6) content of Phycodrys rubens is $35.3 \%$ and Delesseria lancifolia is $31.1 \%$ [2]. It is recorded that Eucheuma cottonii contains 51.56\% PUFA of which $24.98 \%$ eicosapentaenoic acid [3]. Red algae recorded high content of 20:4 and 20:5 fatty acids and 16.4 to $31.8 \mu$ molg- 1 dry wt. glycolipids in compare, green algae contain 4.9 to $23.1 \% 16.4$ fatty acid as well as high amount of 16:0,18:1, and 18:3 fatty acids with 10.5 to $31.8 \mu$ molg-1 dry wt. glycoprotein[5] (Table 1 ).

\begin{tabular}{|c|c|c|c|c|}
\hline \multicolumn{5}{|c|}{ Fatty Acids Composition of Seaweeds (\% Of Dry Wt.) } \\
\hline Species & Sfa & Mufa & Pufa & Trans fat \\
\hline Undaria pinnatifida & 17.5 & 7.8 & 73.7 & 0.3 \\
\hline Porphyra sp. & 35.7 & 18.6 & 34.8 & 0.8 \\
\hline Laminaria sp. & 41.5 & 17.4 & 57.9 & 0.1 \\
\hline Hizikia fusiforme & 28.1 & 13.4 & 71.1 & 0.3 \\
\hline Caulerpa veravelensis & 27.1 & 1.9 & 63.1 & 02 \\
\hline Ulva fasciata & 29.6 & 7.5 & 58.0 & 0.2 \\
\hline Dictyota bartayresiana & 28.9 & 13.1 & 60.8 & 0.2 \\
\hline Caulerpa racemosa & 33.4 & 5.7 & 6.5 & 0.1 \\
\hline Gracilaria corticata & 31 & 3.5 & 60.4 & 0.9 \\
\hline Pyronia tenera & 34.3 & 5.4 & 50.2 & 0.4 \\
\hline Halimeda tuna & 41.9 & 7.9 & 56.8 & 0.4 \\
\hline Caulerpa sertularioides & 41.4 & 2.2 & 51.5 & 0.3 \\
\hline Bryopsis pennata & 42.1 & 6.5 & & \\
\hline
\end{tabular}

\section{Anticholesterol Activity of Seaweeds}

Most notably statins are the cholesterol lowering therapeutics for hypercholesterolemic dyslipidemia. The fucoidans of Cladosiphon okamuranus have cholesterol lowering activity. It has been reported that Palmaria palmata have angiotensin converting Enzyme (ACE) inhibitory activity (0.19-0.78\%). The Omega 3 fatty acids of seaweeds control hypertension and prevent coronary heart disease. The protein hydrolysates of some seaweeds control hypertension and type-II diabetes. Generally, the Omega 3 fatty acids of seaweeds control hypertension and prevent coronary heart disease. Similarly,
Chitosan and Chitin of seaweeds reduced total cholesterol and lowdensity lipoprotein cholesterol. The two important seaweeds such as Ecklonia cava and Undaria pinnatifida showed anti-hypertensive and anti-cholesterol activity. The green seaweed polysaccharides Ulvan extracted from Ulva fasciata have been reported for its anti-hypercholesterolemic activity and it may be also used as natural lipid regulator [6]. The Nanoparticles synthesized from Ulva fasciata polysaccharides also has anti-hypercholesterolemic activity [7]. The ethanol extract and the phlorotanin including eckol and dieckol from Ecklonia stolonifera had been investigated 
for its anticholesterol activity, which revealed that polysaccharides extract has significant anti-hypercholesterolemic activity rather than ethanolic extract, the polysaccharides extract lowered the low density lipo-protein cholesterol and triglycerides including total cholesterol and also higher the high density lipoprotein cholesterol

Table 2: Functional ingredients.
[8]. Algal polysaccharides such as Ulvan, fucoidans, laminarin sulphate, alginate, Rhamnan sulphate, agar and carragenan have been reported for its anti-hyper cholesterol activity and antiatherosclerotic activity [9] (Table 2).

\begin{tabular}{|c|c|c|}
\hline Algae & Functional Ingredients & Possible Health Effect \\
\hline \multirow{3}{*}{ Himanthalia elongate } & PUFAs & Reduce risk of certain heart diseases \\
\cline { 2 - 3 } & Sterols & Reduce total and LDL cholesterol \\
\cline { 2 - 3 } & Soluble fiber & Reduce total and LDL cholesterol \\
\hline \multirow{2}{*}{ Undaria pinnatifida } & PUFAs & Reduce risk of certain heart diseases \\
\cline { 2 - 3 } & Soluble fiber & Reduce total and LDL cholesterol \\
\hline \multirow{2}{*}{ Phorphira spp. } & Sterols & Reduce total and LDL cholesterol \\
\hline \multirow{2}{*}{ Chondrus crispus } & Soluble fiber & Reduce total and LDL cholesterol \\
\hline Cystoseira spp. & Sterols & Reduce total and LDL cholesterol \\
\hline
\end{tabular}

\section{Angiotensin-1 Converting Enzyme (ACE) inhibitor property of marine macro algae}

ACE regulates blood pressure and electrolyte homeostasis. It cleaves angiotensin-I to Angiotensin-II. Angiotensin-II is a powerful vasoconstrictor and salt retaining octapeptide. It also catalyses the inactivation of bradykinin, which is a vasodilator and natrituretic nonapeptide. ACE inhibitor such as alacepril, benazepril, captopril, cilazapril, enalapril, fosinopril, lisinopril, moexipril, perindopril, quinapril, ramipril, tandolapril and zofenopril used for treatment of essential hypertension and heart failure in human but have side effect like cough, taste disturbance and skin rashes. According to Athukorala [10], the water extract of Ecklonia cava reportedly contains higher ACE (angiotensin inhibitory activity) inhibitor activity i.e. 36\% among seven brown algae such as Sargassum fullvelum (24\%), Ishige okamurae (22\%), Sargassum horneri, Sargassum thunbergii is 18 to $17 \%$, Sargassum coreanum and Scytosipon lomentaria (5\%).

\section{Drugs for anti-hypercholesterolemia}

It is reported that Heparin and Captopril are choose drugs for cardiovascular disorder treatment and prevention over 60 years, but it is not orally administrated, so difficult to use for extended therapy [11]. But Captopril has several side effects including cough, taste differences and skin rashes, so difficult to use for medication for cardiac patient [12]. Some market available statins group of medicine which used for lowering low density lipo-protein cholesterol and triglycerides but slightly increase high density lipo-protein cholesterol such as Atorvastatin (Lipitor), Fluvastatin (Lescol XL), Lovastatin (Altoprev), Pitavastatin (Livalo), Pravastatin (Pravachol), Rosuvastatin (Crestor), Simvastatin (Zocor); these drugs have several side effects such as increase blood sugar, pain with soreness of muscles, diarrhoea, constipation, nausea etc. Some resins such as Colesevelam (Welchol), Colestipol (Colestid), Cholestyramine (Prevalite) binds with bile acid and lower the low density lipo-protein cholesterol (LDL), which also have side effects such as heartburn, bloating, constipation, nausea and gas etc. The Ezetimibe commonly known as Zetia and Vytorin decrease LDL by inhibiting the cholesterol absorption, which also develop muscles soreness, fatigue, and stomach pain. Some fibrates such as Lipofen, Antara, Gemfibrozil and statin and calcium channel blocker such as Amlodipine- atorvastatin also decrease the low density lipo-protein cholesterol, triglycerides and increase high density lipo-protein cholesterol. The Evolocumab (Repatha), Alirocumab (Praluent) injection is often used for lowering the high cholesterol of some patients who bear inherited heart disease [13].

\section{Dietic control}

The diet should be containing low saturated fats and without trans-fat, but it should contain high amount of omega-3-fatty acids. Add some dietary protein also which is also helpful to increase the high density lipo-protein cholesterol.

\section{Future prospective}

Seaweeds contains high amount of omega-3 fatty acids including its rich nutrients composition. So, this review may be helpful to include the useful information regarding seaweeds therapeutics application for cardiovascular disease. In future, after further extensive investigations, seaweeds may be applied as therapeutics for cardiovascular disease.

\section{Acknowledgement}

Author is thankful to Department of Science and Technology for their support. Author thanks Dr. P. Anantharaman, Associate professor for support. Author thanks to Dean, C.A.S in Marine Biology, Faculty of Marine Sciences, Annamalai University and all higher authorities of Annamalai University.

\section{Conflict of interest}

There are no conflicts of interest to be declared. 


\section{References}

1. Sudheendran S, Chang CC, Deckelbaum RJ (2010) N-3 vs. saturated fatty acids: effects on the arterial wall. Prostaglandins Leukot Essent Fatty Acids 82(4-6): 205-209.

2. Graeve M, Kattner G, Wiencke C, Karsten U (2002) Fatty acid composition of Arctic and Antarctic macro algae: Indicator of phylogenetic and trophic relationships. Marine Ecology Progress Series 231: 67-74.

3. Matanjun P, Mohamed S, Mustapha MN, Muhammad K (2009) Nutrient content of tropical edible seaweeds, Eucheuma cottonii, Caulerpa lentillifera and Sargassum polycystum. Journal of Applied Phycology 21(1): 75-80.

4. Burtin P (2003) Nutritional value of seaweeds. EJEAFChe 2(4).

5. Dembitsky VM, Pechenkina-shubina EE, Rozentsvet OA (1991) Glycolipids and fatty acids of some seaweeds and marine grasses from the blacksea. Photochemistry 30(7): 2279-2283.

6. Rizk ZM, Aly FH, Matloub AA, Fouad IG (2016) The antihypercholesterolemic effect of ulvan polysaccharide extracted from the green alga Ulva fasciata on aged hypercholesterolemic rats. Asian J Pharm Clin Res 9(3): 165-176.

7. Matloub AA, Abou Samra MM, Salama AH, Rizk ZM, Aly FH, et al. (2018) Cubic liquid crystalline nanoparticles containing a polysaccharide from Ulva fasciata with potent antihyperlipidemic activity. Saudi Pharmaceutical Journal 26(2): 224-231.

8. Yoon YN, Kim HR, Chung HY, Choi JS (2008) Anti-hyperlipidemic effect of an edible brown algae, Ecklonia stolonifera, and its constituents on poloxamer 407-induced hyperlipidemic and cholesterol-fed rats. Archives of Pharmacal Research 31(12): 1564-1571.

9. Patil PK, Le V, Silgar AD, Mei L, Chavarria D, et al. (2018) Algal Polysaccharides as Therapeutic Agents for Atherosclerosis. Frontiers in Cardiovascular Medicine 5(153):1-18.

10. Athukorala Y (2004) Anticoagulative and Antihypertensive Activities of Ecklonia cava. Department of marine Biotechnology, graduate school, Cheju National University, South Korea.

11. Daniel JM, Joseph AT, Phillip JA, Douglas MT, Dana RA (1999) Anticoagulant and antithrombotic activity of maltodopha, a novel sulphated tetrasaccharide. J Pharmaco Experi 288: 516-521.

12. Atkinson AB, Robertson JIS (1979) Captopril in the treatment of clinical hypertension and cardiac failure. The Lancet 2(8147): 836-839.

13. Shalaby AE (2011) Algae as promising organisms for environment and health. Plant Signal Behav 6(9): 1338-1350.

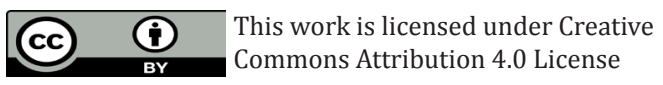

To Submit Your Article Click Here: Submit Article

DOI: $10.32474 /$ LOJPCR.2019.01.000112

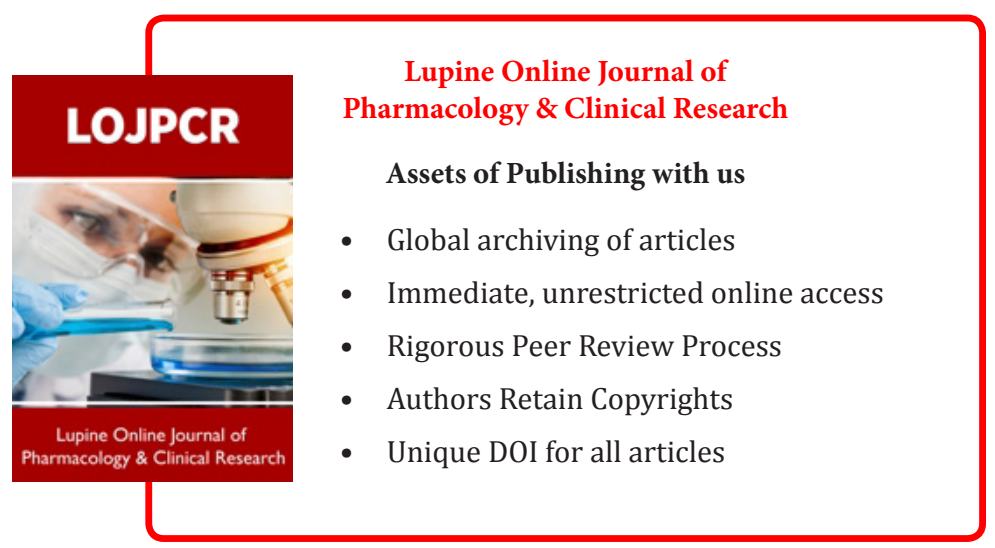

